\title{
ПРАВО
}

УДК 347.763:656.13(4)

DOI dx.doi.org/10.24866/1813-3274/2020-1/103-117

Р. И. Дремлюга ${ }^{1}$, Дальневосточный федеральный университет,

г. Владивосток, Россия

E-mail: dremliuga.ri@dvfu.ru
А. А. Яковенко ${ }^{2}$, Дальневосточный федеральный университет,
г. Владивосток, Россия
E-mail: andrey.drus@yandex.ru

\section{РЕГУЛИРОВАНИЕ ТЕСТИРОВАНИЯ БЕСПИЛОТНОГО АВТОТРАНСПОРТА: ОПЫТ ЕВРОПЫ*}

Аннотация. Развитие технологий автономного автотранспорта является одним из приоритетов в технологическом развитии Российской Федерации. Несмотря на прогресс в данной сфере, вряд ли можно говорить о значимых успехах России во внедрении использования автономного транспорта на дорогах общего пользования. В основе данного исследования лежит утверждение, что правовой режим является либо катализатором, либо замедляющим фактором развития сферы автономного автотранспорта.

Цель исследования - провести анализ правовых норм в сфере тестирования и эксплуатации автономного автотранспорта в Европе. Авторы полагают, что исследуемые европейские страны имеют достаточно проработанную нормативную базу в данной сфере, поэтому их опыт может быть полезен в разработке и модификации российской правовой базы для регулирования отношений в сфере использования

\footnotetext{
${ }^{1}$ Роман Игоревич Дремлюга, кандидат юридических наук, доцент Юридической школы Дальневосточного федерального университета, г. Владивосток, Россия.

${ }^{2}$ Андрей Александрович Яковенко, магистрант Юридической школы Дальневосточного федерального университета, г. Владивосток, Россия.

Для иитирования: Дремлюга Р. И., Яковенко А. А. Регулирование тестирования беспилотного автотранспорта: опыт Европы // Азиатско-Тихоокеанский регион: экономика, политика, право. 2020. № 1. C. $103-117$.

* Исследование выполнено при финансовой поддержке РФФИ в рамках научного проекта № 18-2916129.
}

(С Дремлюга Р. И., Яковенко А. А., 2020 
автономного автотранспорта. Задачи исследования: а) определить нормативную базу, связанную с регулированием отношений по тестированию и эксплуатации автономных транспортных средств; б) выявить позицию лидирующих европейских стран, связанную с вопросами необходимости регулирования таких отношений; в) оценить перспективы возможности заимствования положительной практики регулирования рассматриваемой сферы общественных отношений в правовую действительность Российской Федерации.

Методологической основой исследования послужили диалектический метод познания, общенаучные методы абстрагирования, анализа и синтеза, а также специальные юридические методы (сравнительно-правовой, логико-юридический и др.).

В статье делается вывод, что в процессе создания нормативно правовой базы власти стремятся детально урегулировать исследуемую область общественных отношений. Рассмотренные страны имеют практически схожую модель регулирования, с жёсткими нормативными рамками. Авторы полагают, что некоторые ограничения являются неблагоприятными для развития сектора цифровой экономики. Тем не менее, опыт европейских стран может быть использован в России в первую очередь для определения проблемных точек регулирования и организации контроля за тестированием и использованием автономного автотранспорта.

Ключевые слова: Европейский Союз, регулирование тестирования автономного автотранспорта, беспилотный автотранспорт, цифровая экономика, искусственный интеллект, кибербезопасность, распознавание образов, киберправо, беспилотные транспортные средства, цифровая трансформации, умные вещи, умный город, сравнительное правоведение, сравнительный анализ, новый технологический уклад, право Нидерландов, право Германии, право Великобритании, право информационных технологий, право ИТ. 
Roman I. Dremliuga ${ }^{1}$, Far Eastern Federal University, Vladivostok, Russia E-mail: dreamluck@yandex.ru

Andrey A. Yakovenko ${ }^{2}$, Far Eastern Federal University, Vladivostok, Russia E-mail: andrey.drus@yandex.ru

\section{REGULATION OF AUTONOMOUS VEHICLE TESTING AND USE: EXPERIENCE OF EUROPE*}

Abstract. The development of unmanned (autonomous) vehicle technologies is one of the strategic priorities of the Russian Federation. Despite a great deal of attention to this area, one can hardly speak of any significant success of Russia in introducing the use of autonomous vehicles on public roads. This study is based on the assumption that the legal regime is a catalyst or a deterrent to the development of autonomous motor transport or a deterrent to the development of the autonomous motor transport sector. The aim of the study is to analyze the legal norms in the field of testing and operation of autonomous road transport in Europe. The authors believe that the studied European countries have a sufficiently developed regulatory system in this area; therefore, their experience can be useful in developing and modifying the Russian legal framework to regulate the use of autonomous road transport. The objectives of the study are as follows: a) to define the regulatory framework related to the regulation of relations in the testing and operation of autonomous vehicles; b) to identify the position of the leading European countries related to the issues of the need for regulation and its limits; c) to assess the prospects for the possibility of taking the positive practice of regulation of the considered sphere of social relations into the legal reality of the Russian Federation. The dialectical method of cognition, general scientific methods of abstraction, analysis and synthesis, as well as special legal methods (comparative legal, logical-legal, etc.) served as the methodological basis for the research. The article concludes that in the process of creating a legal system the authorities seek to regulate in detail the area of public relations under study. The countries under study have almost similar model of regulation with rigid normative frameworks. The authors believe that some restrictions are unfavorable for the development of digital economy sectors. Nevertheless, the experience of European countries can be used in Russia first of all to identify problem points of regulation and organization of control over testing and use of autonomous motor vehicles.

\footnotetext{
${ }^{1}$ Roman I. Dremliuga, Associate Professor, School of Law, Far Eastern Federal University, Vladivostok, Russia.

${ }^{2}$ Andrey A. Yakovenko, Master Student, Far Eastern Federal University, Vladivostok. Russia.

For citing: Dremliuga R. I., Yakovenko A. A. Regulation of Autonomous vehicle testing and use: experience of Europe // PACIFIC RIM: Economics, Politics, Law. 2020. No 1. P. 103-117.

* The study was carried out with the financial support of the Russian Federal Property Fund within the scientific project No. 18-29-16129.
} 
Keywords: European Union, regulation of autonomous vehicle testing, unmanned vehicles, digital economy, artificial intelligence, cyber security, pattern recognition, cyberlaw, unmanned vehicles, digital transformation, smart things, smart city, comparative law, new technology, Dutch law, German law, UK law, information technology law, IT law.

В Плане мероприятий Национальной технологической инициативы «Автонет» сказано, что «пик развития технологий автономности придётся на 2020-2030 гг. Наиболее быстрое развитие технологий автономного вождения можно ожидать в сегментах люксовых персональных автомобилей, общественного транспорта, а также караванного вождения при перевозке грузов» [1]. Беспилотный транспорт высокой степени автоматизации - это инновация, которая может быть выгодна и государству, и обществу одновременно.

Развитие технологий беспилотного автотранспорта является одним из приоритетов Российской Федерации. В связи с активным развитием цифрового пространства и более качественным подходом к защите «цифровых» прав населения особый интерес представляет опыт европейских государств по разработке нормативной базы, позволяющей проводить тестирование и вводить в эксплуатацию беспилотный автотранспорт.

На сегодняшний день сформирован рейтинг стран, лидирующих в области внедрения автономных автотранспортных средств на дорогах страны [2]. На примере трёх лидирующих в данном рейтинге стран предлагаем сравнить, как развивается нормативная база в указанной сфере.

Необходимо отметить, что Германия и Нидерланды уже имеют специальные законы, позволяющие тестировать беспилотный автотранспорт. Великобритания пошла по более сложному пути, в настоящий момент ведутся работы по подготовке целого ряда законодательных изменений, которые будут включать в себя не только нормы, регламентирующие процедуру доступа автономного транспорта на дороги общего пользования. Законодатель также разрабатывает нормы, направленные на создание экосистемы, позволяющей сделать автономный транспорт основой транспортной системы страны, с целью улучшения экономического и экологического благосостояния населения.

\section{Нидерланды}

Испытания в этой стране полностью автономных транспортных средств на дорогах общего пользования разрешены с 1 июля 2019 г.

Согласно тексту Закона об экспериментальных автономных транспортных средствах [3] для проведения тестирования автономных транспортных средств, необходимо получить предварительное или временное разрешение. В том случае, если предполагается отсутствие водителя в автономном транспортном средстве, то 
Дремлюга Р. И., Яковенко А. А. Регулирование тестирования беспилотного автотранспорта: опыт Европы

необходимо после консультации с министром юстиции и безопасности (далее министр) получить его разрешение на проведение тестирования.

Министр, давший разрешение на проведение тестирований автономного транспортного средства, несёт ответственность за выданную им лицензию.

Согласно статье 149аб рассматриваемого закона разрешение на проведение тестирования выдается максимум на три года. Разрешение обязательно должно содержать следующие сведения: описание эксперимента, на каких дорогах или участках дорог будет проводиться тестирование, в течение какого периода будет проводиться тестирование, в каких погодных условиях и в какое время суток может проводиться тестирование, возможные исключения из правил, какие меры безопасности предпринимаются в процессе тестирования беспилотного транспорта. В разрешении должна быть указана процедура контроля. Например, необходимо прописать, каким образом министру будет предоставлена возможность контролировать и оценивать ход проведения тестирования.

Министр может отозвать разрешение, если лицо, получившее разрешение, не соблюдает правила и ограничения, прилагаемые к разрешению, и если безопасность дорожного движения находится под угрозой при тестировании беспилотного транспортного средства.

По итогам тестирования Министр должен произвести его оценку и составить отчёт. Министр в течение пяти лет после вступления в силу настоящего Закона должен подготовить доклад об эффективности принятого Закона на практике.

\section{Великобритания}

В Соединенном Королевстве создан правительственный департамент, Центр подключённых и автономных транспортных средств (далее - center of autonomous vehicle или (AV), который отвечает за разработку законодательства, регулирующего проведение испытаний автономных транспортных средств на автомагистралях в стране. Существуют также локальные нормы, регулирующие процедуру тестирования автономного автотранспорта в отдельных городах, например, Лондон и Ковентри.

C 2018 г. по заказу CAV независимой Юридической комиссией ведётся работа над созданием нормативной базы по регулированию тестирования и введения в эксплуатацию автоматизированных автотранспортных средств. В процессе разработки и обсуждения разработаны консультативный документ № 1 и № 2 , документы представляют собой анализ действующего законодательства Великобритании в сфере автомобильного транспорта. На основании проведённого анализа комиссией должны быть выработаны рекомендации по интеграции беспилотного транспорта в транспортную систему страны с конкретными предложениями по изменению нормативной базы. Принятые рекомендации должны найти своё отражение в изменениях в законодательстве Великобритании к 2021 г. [4]. 
В первом консультативном документе рассматриваются вопросы общего характера для автоматизированных транспортных средств, которые могут передвигаться самостоятельно только часть поездки, и для транспортных средств, которые могут быть полностью автономными. В частности, документ касается вопросов регулирования обеспечения безопасности наряду с гражданской и уголовной ответственностью за причинение вреда транспортным средством.

В ходе разработки консультативных документов № 1 и № 2 независимая Юридическая комиссия провела анализ закона об автоматизированных и электрических транспортных средствах 2018 г. [5].

В соответствии с этим законом страховщик несёт прямую ответственность за выплату компенсации жертве. Страховщик может потребовать возмещения ущерба от любой стороны, ответственной за аварию.

В соответствии с Законом об Автоматизированных и электрических транспортных средствах (англ. - «Automated and Electric Vehicles»; далее - AEV) 2018 г., если ДТП произошло по вине полностью автономного транспортного средства, в соответствии с условиями Закона страховщик несёт прямую ответственность за причинённый ущерб. Цель данной нормы - позволить в кратчайшие сроки потерпевшему получить возмещение ущерба. Согласно другим положениям закона после того, как страховщик и потерпевшее лицо пришли к консенсусу, страховщик имеет право потребовать возмещения ущерба от других лиц, ответственных за ДТП, например, от производителя транспортного средства.

Раздел 1 закона AEV обеспечивает необходимую законодательную основу для предоставления компенсации жертвам в тех случаях, когда был нанесён ущерб автономным транспортным средством [5].

Согласно статье 6 закона о AEV в тех случаях, когда дорожно-транспортное происшествие в той или иной степени произошло по вине пострадавшей стороны, правонарушение будет квалифицировано как халатность ${ }^{1}$, а размер компенсации будет определён судом.

Для применения разработанных положений об ответственности причиной аварии должно стать само автономное транспортное средство. В настоящее время ведутся дебаты о причинно-следственной связи некоторых видов неисправностей [6]. Например, если автономное транспортное средство совершает маневр, чтобы избежать столкновения с велосипедистом-нарушителем, и врезается в припаркованный автомобиль, будет ли страховщик нести ответственность за аварию, даже если вина полностью лежит на велосипедисте? Если у велосипедиста недостаточно средств для исполнения судебного решения, то право страховщика на возмещение

\footnotetext{
${ }^{1}$ Речь о понятии халатности в английском праве. Англ. - negligence. 
Дремлюга Р. И., Яковенко А. А. Регулирование тестирования беспилотного автотранспорта: опыт Европы

ущерба с велосипедиста будет неэффективным. В таких случаях в консультативных документах предлагается оставить решение данных вопросов суду.

Для разрешения судебных споров должны использоваться собранные автомобилем данные: место нахождения автомобиля, лицо, управлявшее автомобилем, нанесённый ущерб. Однако проблема заключается в том, что автоматизированные транспортные средства генерируют большой объём цифровых данных, который требует значительных вычислительных мощностей для обработки и хранения. Поэтому в консультативных документах поднимается вопрос о том, какие данные необходимо сохранить. Особое внимание уделено информации, которая может оказаться необходимой значительно позже предполагаемого инцидента.

В настоящее время ведутся переговоры на уровне ЕС о стандартизации данных [7], которые необходимо хранить после происшествия. Эти меры могут пригодиться в тех случаях, когда автономная система зафиксирует, что произошло столкновение. Однако соответствующие данные могут не сохраниться, когда инцидент не связан с прямым столкновением и автоматизированная система вождения не в состоянии обнаружить факт дорожно-транспортного происшествия [6].

Сроки подачи иска в соответствии с законом об AEV соответствуют принципам гражданского права. Как правило, истец, получивший телесные повреждения, должен подать иск к страховщику в течение трёх лет со дня происшествия. Однако в некоторых случаях срок исковой давности может быть увеличен (например, если в момент аварии истец был ребёнком).

Право на предъявление иска к страховщику в соответствии с законом AEV предполагает кратчайшие сроки компенсации ущерба пострадавшему. Однако это не означает, что юридическая ответственность за несчастный случай полностью возложена на страховщиков. Согласно Закону о защите прав потребителей 1987 г. страховщик может предъявить производителю или поставщику иск либо в соответствии с Законом о защите прав потребителей 1987 г., либо в рамках деликта о халатности (или, в Шотландии, деликт).

В соответствии с Законом о защите прав потребителей 1987 г. за дефектное программное обеспечение, встроенное в физический носитель информации, например, в транспортное средство, может быть истребована компенсация. Однако существует некоторая неопределённость в регулировании компенсации в отношении вреда, причинённого по вине «чистого» программного обеспечения, разработанного отдельно от физического носителя, в частности транспортного средства. Таким образом, могут возникнуть проблемы по выплате компенсации в случае, когда программное обеспечение и транспортное средство производятся разными организациями.

Регулирование дорожного движения в значительной степени связано с публичным правом. При разработке первого консультативного документа было про- 
анализировано 71 преступление (правонарушение) ${ }^{1}$, которое может быть совершено водителем. При привлечении водителя к ответственности оценивается: состояние водителя; наличие страховки; пригодность транспортного средства к эксплуатации; сообщение о произошедшем дорожно-транспортном происшествии; и даже поведение пассажиров (например, пристёгнуты ли дети ремнями безопасности).

В ходе разработки консультативного документа не было обнаружено ни одной нормы, которая препятствовала автоматизированному вождению в целом. Тем не менее, некоторые нормативные предписания могут препятствовать определённым видам автоматизации и автономности.

В 107-й статье Правил дорожного движения (строительство и эксплуатация) 1986 г. Великобритании [8] запрещается выезжать на дорогу транспортному средству, которое обслуживается лицом, не имеющим лицензии на вождение.

Транспортное средство может «находиться в присутствии» лица, находящегося рядом с транспортным средством или в центре дистанционного управления. Однако положения статьи 107 не могут быть применены к некоторым видами высокоавтоматизированных транспортных средств в тех случаях, когда транспортное средство является пустым и не управляемым дистанционно, либо когда единственные пассажиры в транспортном средстве не имеют лицензии на управление им.

Многие правонарушения возникают непосредственно при управлении транспортным средством. Примерами могут служить опасная езда, вождение без должной осторожности, несоблюдение знаков дорожного движения или превышение скорости. По мнению независимой Юридической комиссии, ответственной за создание консультативного документа № 1, когда автотранспортное средство находится в полностью автономном режиме вождения, к ответственности за несоблюдение правил дорожного движения должен быть привлечён субъект, отвечающий за настройку автоматизированной системы вождения перед совершённой поездкой. Комиссия делает акцент на том, что пользователь не считается водителем, пока транспортное средство работает автономно. Правило применимо для ДТП, попадающего в сферу действия уголовного права. Вместо того, чтобы классифицировать транспортное средство в качестве водителя, предлагается, что на пользователя будут распространяться конкретные уголовно-правовые нормы, при применении которых будут учитываться требования по квалификации и пригодности к управлению. Таким образом, может возникнуть ситуация, когда будет причинена смерть или наступят другие тяжкие последствия в ходе эксплуатации транспортного средства в автономном режиме с нарушением правил дорожного движения, но к ответственности не будет привлечено ни одно лицо.

\footnotetext{
${ }^{1}$ В английском праве нет чёткого отграничения преступлений от административных правонарушений. 
Дремлюга Р. И., Яковенко А. А. Регулирование тестирования беспилотного автотранспорта: опыт Европы

Если пользователи больше не несут ответственности за нарушения, совершённые во время автономного вождения, то какие правовые последствия могут наступить в случае, если автономное транспортное средство совершает маневр, который был бы квалифицирован как преступное деяние, если совершён человеком? Политика британского правительства заключается в том, чтобы автоматизированные системы вождения неукоснительно соблюдали установленные действующим законодательством предписания. Однако исключения всё же могут иметь место.

Национальная комиссия по транспорту (далее - НКТ) отмечает, что существующие меры наказания за нарушение правил дорожного движения прямо направлены на то, чтобы повлиять на поведение водителей-людей. Без адаптации действующие меры наказания вряд ли будут эффективными при привлечении к ответственности производителей.

HКТ рекомендует, чтобы каждая автоматизированная система вождения (далее - ADS) поддерживалась организацией автоматизированных систем вождения [9] (далее - ADSE) - орган, который будет выдавать разрешения на эксплуатацию). Производители или разработчики, желающие получить разрешение на тестирование и эксплуатацию ADS, должны будут внести систему в реестр. Каждая ADS, указанная в реестре как способная к автономному управлению, должна быть поддержана ADSE. B случае сбоев или нарушений в работе ADS могут налагаться следующие виды санкций: уведомления об усовершенствованиях, штрафы и отзыв разрешения на деятельность.

Несмотря на то, что ADS должна быть запрограммирована на то, чтобы не превышать ограничения скорости, нарушения скоростного режима всё же могут происходить по разным причинам. Примеры таких нарушений содержатся в главе 7 пункта 7.30 Консультативного документа № 1: власти могли не сообщить о временном ограничении скорости; лицо, ответственное за транспортное средство, возможно, не обновило программное обеспечение (или загрузило несанкционированное программное обеспечение); или система могла выйти из строя [6] ${ }^{1}$. Если в момент превышения скорости автомобиль передвигался автономно, то зарегистрированный владелец обязан об этом сообщить и предоставить соответствующие данные в полицию. После этого полиция проведёт расследование причин нарушения скоростного режима.

Если проблема связана с программным обеспечением, обеспечивающим автономное движение, этот вопрос следует передать на рассмотрение в агентство по обеспечению безопасности. Агентство уполномочено проводить расследование о причинах некорректной и опасной работы. Оно будет иметь полномочия налагать на ADSE ряд поэтапных санкций, включая уведомления о необходимости усовер-

1 Automated Vehicles // https://s3-eu-west-2.amazonaws.com/lawcom-prod-storage-11jsxou24uy7q/upl oads/2018/11/6.5066_LC_AV-Consultation-Paper-5-November_061118_WEB-1.pdf. 
шенствования ADS, штрафы, приостановку деятельности и (в наиболее серьёзных случаях) отзыв лицензии ADS. Таким образом, к разработчику программного обеспечения могут быть применены серьёзные меры, если его некорректная работа вызвала нарушение правил дорожного движения.

Пользователь может самостоятельно управлять транспортным средством, только когда транспортное средство может безопасно передать управление человеку. В связи с этим пользователь, которому было делегировано управление автономным транспортным средством, должен иметь право на осуществление этой деятельности. Предполагается, что такой водитель может быть привлечён к уголовной ответственности в следующих случаях: (1) не имеет водительских прав на транспортное средство; (2) был лишён права управления транспортным средством; (3) иметь зрение, не соответствующее установленным требованиям для управления транспортным средством; (4) имеет определённую группу инвалидности, не дающую право управления транспортным средством; (5) не имеет права на вождение вследствие алкогольного или наркотического опьянения [6].

Рассматриваемый консультативный документ вводит понятие ответственного пользователя. Согласно пункту 3.45 ответственным пользователем является лицо, находящееся в автономном транспорте, которое имеет право на управление автономным транспортным средством в случае необходимости.

Буквально это означает, что лицо находится «на сиденье водителя». Однако в настоящее время данная категория расширяется и в неё могут войти и лица, не находящиеся в автомобиле. Сюда могут входить, например, операторы, контролирующие работу автономного транспортного средства удалённо.

В настоящее время рассматриваются новые обязанности, возлагаемые на пользователя, которые специфичны для автоматизации вождения и не имеют прямого аналога в действующем законодательстве. Например, необходимость обязать пользователя взять на себя управление транспортным средством на определённом участке дороги. Кроме того, нормативные предписания могут касаться составления предварительного маршрута передвижения. Например, несанкционированный съезд с разрешённого участка маршрута, разрешённого для эксплуатации в полностью автономном режиме, может быть административно или уголовно наказуемым.

В уголовном праве Великобритании существует восемь типов уголовных преступлений, связанных с причинением смерти или серьёзных травм в результате управления транспортным средством. В случае отсутствия человека за рулём другие лица привлекаться к ответственности не должны. При рассмотрении вопроса о привлечении к ответственности очевидны два возможных пробела в законодательстве.

Первый - когда смерть или серьёзные травмы вызваны вмешательством третьих лиц: например, какое-либо лицо закрасило дорожную разметку, испортило дорожные знаки или мешает работе датчиков. Второй - когда смерть или серьёзные 
Дремлюга Р. И., Яковенко А. А. Регулирование тестирования беспилотного автотранспорта: опыт Европы

травмы вызваны нарушениями в работе программного обеспечения автомобиля. Такие виды деяний не охватываются существующими нормами ответственности за общественно опасные деяния.

В первом консультативном документе также исследуется вопрос: как будет применяться закон, если смерть или серьёзная травма была вызвана противоправными действиями организации, которая разрабатывает автоматизированную систему вождения? К возможным нарушениям относятся: 1) тесты, которые должны были быть проведены, но не проводились; 2) сокрытие отрицательных результатов тестирования; 3) установка программного обеспечения, которое способно улучшить результаты моделируемых на компьютере тестов в сравнении с тестами в реальном мире; 4) отключение критических элементов безопасности.

В случае смерти лица в результате дорожно-транспортного происшествия с участием автономного транспортного средства к уголовной ответственности за непредумышленное убийство может быть привлечена компания-разработчик. В соответствии с Законом о непредумышленном и корпоративном убийстве 2007 г. [10] организация виновна в непредумышленном убийстве, если способ управления или организация её деятельности являются причиной смерти человека или высшее руководство компании совершило ошибки, которые являются «существенным элементом» правонарушения.

Существуют две основные проблемы, связанные с привлечением к ответственности согласно вышеописанным нормам.

Во-первых, рассматриваются только случаи с летальным исходом, а это значит не регламентирована ответственность за причинение тяжких телесных повреждений. Во-вторых, могут возникнуть трудности применения норм об ответственности к крупным многонациональным компаниям. Как отмечает Селия Уэллс, большинство компаний, привлечённых к ответственности за непредумышленное корпоративное убийство, были небольшими или средними по размеру, в которых отдельные директора принимают непосредственное участие в принятии повседневных решений. Напротив, в крупных компаниях со сложной структурой управления руководители высшего звена могут быть дистанцированы от непосредственного принятия таких решений и избежать ответственности.

Таким образом, консультационный документ 1 описывает правонарушения, непосредственно связанные с управлением транспортным средством, такие как опасное вождение или превышение скорости. Также документ касается правонарушений, которые не вытекают непосредственно из задачи вождения, например, правонарушения, связанные со страхованием и пригодностью транспортного средства к эксплуатации на дороге.

Второй консультационный документ рассматривает высокоавтоматизированные пассажирские перевозки (далее - HARPS). 
Если консультативный документ 1 имел целью рассмотреть общие вопросы регулирования отношений, связанных с функционированием автономных транспортных средств, например, вопросы наступления гражданской и уголовной ответственности, то второй документ фокусируется на использовании автономных транспортных средств для развития сферы услуг перевозки.

Руководствуясь названными документами, административно-территориальные единицы Великобритании должны формировать свои планы и стратегии по развитию автономного транспорта. То есть, хотя данные консультационные документы в настоящий момент не имеют нормативной силы, они влияют на принятие нормативных и организационных решений. Например, Большой Манчестер или Глазго сформировали свои планы и стратегии по развитию сферы беспилотного автотранспорта, основываясь на приведённых документах [11].

\section{Германия}

21 июня 2017 г. в Германии был принят закон о легализации автоматических транспортных средств (далее - AV Bill [12]). Закон AV Bill изменяет действующий Закон о дорожном движении в Германии и определяет требования для использования на дорогах общего пользования высоко автоматизированных и полностью автоматизированных транспортных средств. В законе определяются права и обязанности водителя при активации автоматического режима вождения. Согласно AV Bill водитель и «владелец» (нем. - Halter) продолжают нести ответственность, даже если транспортное средство находится в автоматическом режиме вождения. Водитель может избежать ответственности, если он используют автоматический режим вождения, следуя выработанным правилам и рекомендациям. Автомобили должны быть оснащены чёрным ящиком, чтобы определить, под чьим контролем находилось транспортное средство: водителя или автономной системы во время аварии, так как это поможет водителю / «владельцу» (на практике - страховой компании) доказать, что стало причиной аварии.

Среди основных положений AV Bill можно выделить следующие:

1. В § 1а определены понятия высоко и полностью автоматизированных транспортных средств. В соответствии с этим определением, в частности, система должна быть в состоянии соблюдать правила дорожного движения, распознавать, когда необходимо передать контроль водителю, а также позволять водителю в любое время вручную деактивировать автоматический режим вождения.

2. Согласно $\S 1 \mathrm{~b}$ использование автоматизированных транспортных средств разрешается в тех пределах, которые определены производителями автомобилей, например, недопустимо покидать водительское сиденье, когда транспортное средство находится в автоматическом режиме. Система должна уведомить водителя о запрете совершения данного действия, в случае если он предпримет попытку сделать это. 
3. Согласно пункту $1 \S 1 \mathrm{~b}$ водитель имеет право отвлечь внимание во время движения. Однако, чтобы восстановить контроль над транспортным средством без излишних задержек, водитель должен быть заблаговременно уведомлен системой, что автоматический режим вождения больше не может функционировать должным образом.

4. Согласно пункту $3 \S 1$ с наблюдается 100 -процентное увеличение пределов максимальной ответственности в соответствии с Законом о дорожном движении (например, максимальный размер выплат увеличен до 10 миллионов евро за смерть или травму; максимум до 2 миллионов евро за повреждение имущества).

5. Согласно § 63а транспортные средства с высоко или полностью автоматизированными функциями вождения должны быть оборудованы чёрным ящиком. В случае аварии чёрный ящик определяет, кто контролировал транспортное средство: водитель или система управления транспортным средством, и таким образом выясняет, лежит ли ответственность на водителе или на изготовителе. Такой подход коррелирует с Британским о хранении информации для установления степени виновности в ДТП.

Обзор практики регулирования тестирования автономного транспорта в Европе показывает, что в настоящее время только начинает формироваться нормативная база по регулированию тестирования автономных транспортных средств. При этом основной акцент делается на необходимости создания и увеличения количества автономного общественного транспорта и уменьшения количества личных автотранспортных средств с целью сокращения дорожных заторов и улучшения экологической обстановки в стране. Важным требованием является возможность восстановить картину событий при ДТП посредством хранения данных об эксплуатации автономного автомобиля. При этом, как правило, наблюдается «зарегулированность» в отношении предоставления разрешения на тестирование автономного транспорта, что выражено в необходимости детально описать любые условия тестирования транспортного средства, включая погоду и время суток. Нарушение какого-либо условия может повлечь за собой дальнейший отзыв разрешений на тестирование транспортных средств. Такая практика безусловно направлена на минимизацию рисков, связанных с тестированием автономных транспортных средств, однако это может повлечь за собой замедление развития данной сферы.

\section{Список литературы}

1. План мероприятий («дорожная карта») Национальной технологической инициативы «Автонет» (приложение № 2 к протоколу заседания президиума Совета при Президенте РФ по модернизации экономики и инновационному развитию России от 24.04.2018 № 1). - URL: http://www.consultant.ru/document/cons _doc_LAW_309650/ (дата обращения: 19.05.2020). 
2. Europe autonomous car market: Top 10 countries leading the race in 2019. URL: https://siliconcanals.com/news/europe-autonomous-car-market-top-10-countriesleading-the-race-in-2019/ (дата обращения: 19.05.2020).

3. Experimenteerwet zelfrijdende auto's. - URL: https://www.eerstekamer.nl/w etsvoorstel/34838_experimenteerwet (дата обращения: 19.05.2020).

4. Law Commission. - URL: https://www.lawcom.gov.uk/project/automatedvehicles/ (дата обращения: 19.05.2020).

5. Automated and Electric Vehicles Act 2018. - URL: http://www.legislat ion.gov.uk/ukpga/2018/18/contents/enacted (дата обращения: 19.05.2020).

6. Automated Vehicles. A joint preliminary consultation paper. 08 November 2018. - URL: https://s3-eu-west-2.amazonaws.com/lawcom-prod-storage11jsxou24uy 7q/uploads/2018/11/6.5066_LC_AV-Consultation-Paper-5-November_061118_WEB1.pdf (дата обращения: 19.05.2020).

7. European Commission, Access to In-Vehicle Data and Resources, Final Report (May 2017). - URL: https://ec.europa.eu/transport/sites/transport/files/2017-05access-to-in-vehicle-data-and-resources.pdf (дата обращения: 19.05.2020).

8. The Road Vehicles (Construction and Use) Regulations 1986. - URL: http://www.legislation.gov.uk/uksi/1986/1078/contents/made (дата обращения: 19.05.2020).

9. Changing driving laws to support automated vehicles - URL: https://www.n tc.gov.au/sites/default/files/assets/files/NTC\%20Policy\%20Paper\%20-\%20Changing\% 20driving\%20laws\%20to\%20support\%20automated\%20vehicles.pdf (дата обращения: 19.05.2020).

10. Corporate Manslaughter and Corporate Homicide Act 2007. - URL: http://www.legislation.gov.uk/ukpga/2007/19/contents (дата обращения: 19.05.2020).

11. Automated Vehicles: Consultation Paper 2 on Passenger Services and Public Transport. - URL: https://s3-eu-west-2.amazonaws.com/lawcom-prod-storage-11jsxou 24uy7q/uploads/2019/10/Automated-Vehicles-Consultation-Paper-final.pdf (дата обращения: 19.05.2020).

12. Achtes Gesetz zur Änderung des Straßenverkehrsgesetzes 20.06.2017. - URL: https://www.bgbl.de/xaver/bgbl/start.xav?startbk=Bundesanzeiger_BGBl\#_bgbl_\%2F $\% 2 \mathrm{~F} * \% 5 \mathrm{~B} \% 40$ attr_id\%3D\%27bgbl117s1648.pdf\%27\%5D_1586095397766_ (дата обращения: 19.05.2020).

\section{References}

1. Plan of measures («road map») of the National Technological Initiative "Avtonomet» (Annex N 2 to the minutes of the meeting of the Presidium of the Presidential Council on Economic Modernization and Innovative Development of Russia from 24.04.2018 № 1). Available at: http://www.consultant.ru/document/cons_doc_ $L A W \_309650 /$ (accessed 19 May 2020). (In Russian). 
2. $\quad$ Europe autonomous car market: Top 10 countries leading the race in 2019. Available at: https://siliconcanals.com/news/europe-autonomous-car-market-top-10countries-leading-the-race-in-2019/ (accessed 19.05.2020).

3. Experimenteerwet zelfrijdende auto's. Available at: https://www.eersteka mer.nl/wetsvoorstel/34838_experimenteerwet (accessed 19 May 2020).

4. Law Commission. Available at: https://www.lawcom.gov.uk/project/auto mated-vehicles/ (accessed 19 May 2020).

5. Automated and Electric Vehicles Act 2018. Available at: http://www.legislati on.gov.uk/ukpga/2018/18/contents/enacted (accessed 19 May 2020).

6. Automated Vehicles. A joint preliminary consultation paper. 08 November 2018. Available at: https://s3-eu-west-2.amazonaws.com/lawcom-prod-storage11jsx ou24uy7q/uploads/2018/11/6.5066_LC_AV-Consultation-Paper-5-

November_061118_WEB-1.pdf (accessed 19 May 2020).

7. European Commission, Access to In-Vehicle Data and Resources, Final Report (May 2017). Available at: https://ec.europa.eu/transport/sites/transport/files/2017-05access-to-in-vehicle-data-and-resources.pdf (accessed 19 May 2020).

8. The Road Vehicles (Construction and Use) Regulations 1986. Available at: http://www.legislation.gov.uk/uksi/1986/1078/contents/made (accessed 19 May 2020).

9. Changing driving laws to support automated vehicles. Available at: https://www.ntc.gov.au/sites/default/files/assets/files/NTC\%20Policy\%20Paper\%20$\% 20$ Changing\%20driving\%20laws\%20to\%20support\%20automated\%20vehicles.pdf (accessed 19 May 2020).

10. Corporate Manslaughter and Corporate Homicide Act 2007. Available at: URL: http://www.legislation.gov.uk/ukpga/2007/19/contents (accessed 19 May 2020).

11. Automated Vehicles: Consultation Paper 2 on Passenger Services and Public Transport. Available at: https://s3-eu-west-2.amazonaws.com/lawcom-prod-storage11jsxou24uy7q/uploads/2019/10/Automated-Vehicles-Consultation-Paper-final.pdf (accessed 19 May 2020).

12. Achtes Gesetz zur Änderung des Straßenverkehrsgesetzes 20.06.2017. Available at: https://www.bgbl.de/xaver/bgbl/start.xav?startbk=Bundesanzeiger_BGBl\# __bgbl_\%2F\%2F*\%5B\%40attr_id\%3D\%27bgbl117s1648.pdf\%27\%5D_15860953977 66 (accessed 19 May 2020). 